\title{
METODOLOGIA CIENTÍFICA: ANÁLISE E REFLEXÃO SOBRE A PERCEPÇÃo DOS GRADUANDOS
}

\author{
SCIENTIFIC METHODOLOGY: ANALYSIS AND REFLECTION ON \\ PERCEPTION OF GRADUANDS
}

\author{
Francisco Welde Araújo Rodrigues ${ }^{1}$; Aretuza Bezerra Brito Ramos ${ }^{2}$
}

\begin{abstract}
RESUMO
A formação acadêmica consiste no aprimoramento de conceito e conhecimento que se interliga através de métodos e ferramentas, que são capazes de proporcionar segurança e autonomia para os graduandos. Nesse sentido, o objetivo principal da Metodologia Cientifica é estudar os métodos, formas ou instrumentos necessários para a construção de uma pesquisa científica, podendo fornecer um pensamento crítico ao pesquisador. Assim, o presente estudo foi realizado no Sertão Central Pernambucano, e teve o objetivo de analisar os impactos da Metodologia Cientifica na formação de estudantes de Licenciatura, tanto em sua vida profissional, quanto social. Utilizou-se de métodos indutivos através de uma pesquisa qualitativa, com o intuito de realizar uma analise ampla, frente às dificuldades encontradas pelos graduandos com relação aos métodos científicos. A pesquisa foi desenvolvida em duas etapas, sendo uma delas o estudo de campo. Constatou-se que, embora possuam dificuldades, os discentes apresentaram conhecimentos advindos do Ensino Médio ou até mesmo empírico a respeito do tema abordado. O nível de conhecimento das produções acadêmicas foi percebido durante um avanço gradativo, a partir do ingresso no Ensino Superior. Percebe-se também que, os métodos científicos são importantes na formação acadêmica, pois os discentes argumentam ter melhoria na escrita, tendo uma visão mais ampla com relação a produções textuais e aprimoramento dos conhecimentos, passando a produzir trabalhos com maior consistência. Quanto ao contexto profissional e pessoal, os entrevistados afirmam ter o currículo enriquecido a partir da Metodologia Científica, tornando-os críticos a determinadas situações. Diante do exposto percebe-se que é necessária a inserção definitiva de métodos científicos desde a Educação Básica, uma vez que a Metodologia Cientifica é importante na vida acadêmica, profissional, pessoal e cultural dos graduandos, transformando-os e gerando impactos em si mesmo e na sociedade.
\end{abstract}

Palavras-Chave: Pesquisa, Graduação, Discente, Educação Básica.

\begin{abstract}
Academic training consists of improving the concept and knowledge that is interconnected through methods and tools that are capable of providing security and autonomy for undergraduates. In this sense, the main objective of the Scientific Methodology is to study the methods, forms or instruments necessary for the construction of a scientific research, and can provide critical thinking to the researcher. Thus, the present study was carried out in the Sertão Central Pernambucano, and had the objective of analyzing the impacts of Scientific Methodology in the training of undergraduate students, both in their social and professional life. Inductive methods were used through a qualitative research, in order to carry out a broad analysis, in the face of difficulties encountered by undergraduates in relation to scientific methods. The research was developed in two stages, one of them the field study. It was verified that, although they have difficulties, the students presented knowledge coming from the Teaching Medium or even empiric one on the subject approached. The level of knowledge of

\footnotetext{
1 Licenciatura em Ciências Biológicas, Faculdade de Ciências Humanas do Sertão Central, franciscoweldearaujo@outlook.com

${ }^{2}$ Mestre em Gestão Ambiental, Faculdade de Ciências Humanas do Sertão Central, brito.ramos.ab@gmail.com
}

[215] 
the academic productions was perceived during a gradual advance, from the entrance in the Higher Education. It is noticed that, the scientific methods are important in the academic formation, since the students argue to have improvement in the writing, having a wider vision with respect to textual productions and improvement of the knowledge, happening to produce works with greater consistency. Regarding the professional and personal context, the interviewees affirm that the curriculum is enriched from the Scientific Methodology, making them critical to certain situations. In view of the above, it is necessary to insert scientific methods since Basic Education, since Scientific Methodology is important in the academic, professional, personal and cultural life of the undergraduate students, transforming them and generating impacts in themselves and in society.

Keywords: Research, Graduation, Student, Basic Education.

\section{INTRODUÇÃO}

Estimular o "desenvolvimento do espírito científico e do pensamento reflexivo" é um dos objetivos do Ensino Superior brasileiro (BRASIL, 1996) e através da disciplina de Metodologia Cientifica é possível proporcionar à inserção a prática cientifica, sendo importante na formação e lapidação do discente, garantindo ao futuro profissional uma visão mais atuante e crítica do processo de formação e renovação de informações (BARIN, CUNHA E ELLENSOHN, 2009).

Metodologia Cientifica significa o estudo dos métodos, formas, ou instrumentos necessários para construção de uma pesquisa cientifica (OLIVEIRA E VALENÇA, 2015). Assim, é uma disciplina a serviço da ciência, sendo percebida como uma notável interferência e influência na vida pessoal e social dos graduandos, uma vez que os mesmos são estimulados a fazer autocritica em relação às suas pesquisas, que devem ser examinadas sob dois pontos de vista, podendo ser diferenciado o que é verdadeiro e fictício (PRODANOV, 2013).

Para Severino (2000), a mediação necessária e eficaz para o processo de ensino/aprendizagem, pois só aprende e só ensina pela efetiva pratica da pesquisa, tendo dimensões sociais através da perspectiva da extensão. Deste modo, tendo em vista a importância dos métodos científicos no processo de formação acadêmico, que visa inserir o discente no contexto social e profissional, tornou-se necessário à execução de um estudo a cerca da percepção de Metodologia Cientifica na formação dos graduandos de um curso de Licenciatura do Sertão Central Pernambucano e seus impactos na vida social e profissional.

\section{FUNDAMENTAÇÃO TEÓRICA}

Métodos científicos podem ser considerados como uma coleção de fatos, reunidos ao longo de séculos, a partir da contribuição das academias, universidades e cientistas, que tem como objetivo o aperfeiçoamento da ciência, de pressupostos para realizar e apresentar um trabalho de pesquisa, visando à eficácia de seus resultados (KAUARK, MANHÃES E 


\section{MEDEIROS, 2010).}

Oliveira e Valença (2015) afirmam que a Metodologia Cientifica significa o estudo dos métodos, da forma e dos instrumentos necessários para construção de produções científicas, configurando-se uma disciplina a serviço da ciência.

Nesse sentido, a formação acadêmica consiste no aprimoramento de conceito e conhecimento que se interliga através de métodos e ferramentas que são capazes de proporcionar segurança e autonomia para graduandos, e assim, estimular os estudantes, a fim de que busquem motivação para encontrar respostas respaldadas às suas indagações e sistematizá-las através de procedimentos metodológicos pertinentes (PRODANOV, 2013). Desta forma, a disciplina de Metodologia Cientifica deve resgatar no aluno a capacidade de pensar de uma forma espontânea levando-o a um nível reflexível, além de buscar a construção do pensamento crítico (LIBÂNO, 2001).

De acordo com Gerhardt e Silveira (2009), os métodos científicos são as formas mais seguras inventadas pelos homens para controlar o movimento das coisas que cerceiam um fato e montar formas de compreensão adequadas dos fenômenos. Falcão Júnior et al. (2012), afirmam que para que esses efeitos ocorram é necessário ter uma referência que auxilie em julgamentos, podendo-se concluir que a normatização é uma exigência para facilitar a apreciação dos trabalhos.

Santos, Anjos e Almeida (2013), afirmam que é válido salientar a necessidade de uma sustentável base metodológica que incentive a pratica cientifica como instrumento estritamente entrelaçado ao processo de formação ética e profissional dos graduandos, e Sampaio (2013) defende que o pesquisador deve ter no projeto a base de sua pesquisa para o desenvolvimento das atividades de construção do trabalho acadêmico com um norteamento adequado e que proporcione a cientificidade ao trabalho.

Desta forma, a iniciação cientifica é um dever do Ensino Superior, como apresentado na Lei de Diretrizes e Bases da Educação Nacional (BRASIL, 1996) e não deve representar uma atividade eventual ou esporádica, devida o baixo grau de exploração de métodos científicos por parte das instituições de ensino, sendo causa de desistência de discentes por desconhecimento de termos científicos (MAIA, 2008).

Segundo Oliveira e Valença (2015), a "produção do conhecimento científico exige algumas regras/métodos imprescindíveis para o seu sucesso", pois um trabalho científico "não nasce do vazio e muito menos deve ser escrito de qualquer forma”. Isto quer dizer que, além do detalhamento científico necessário, a escrita tem que ser clara e acadêmica.

Desse modo, os trabalhos acadêmicos geram angústia e muitas vezes são vistos como 
“obstáculos" para obtenção de uma nota satisfatória na disciplina específica, considerando assim que os discentes necessitam exercitar a habilidade da autoria frente às reflexões e criticidade do que é produzido (FREITAS, 2012).

\section{METODOLOGIA}

O estudo foi realizado na Faculdade de Ciências Humanas do Sertão Central, localizada em Salgueiro-PE, especificamente em um dos cursos de Licenciatura da instituição, onde foram utilizados métodos indutivos através de uma pesquisa qualitativa, com uma análise ampla, frente às dificuldades encontradas pelos graduandos com relação aos métodos científicos.

A pesquisa foi desenvolvida em duas etapas, sendo a primeira a realização de um levantamento bibliográfico a respeito do conteúdo programático da disciplina de Metodologia Cientifica apresentada nos cursos de graduação da faculdade. Vale salientar que, essa disciplina é ministrada no $4^{\circ}$ período do curso de licenciatura analisado, tendo uma carga horária total de 60 horas, configurando assim o primeiro contato oficial com o método científico, culminando com a produção do Trabalho de Conclusão de Curso (TCC) no $8^{\circ}$ e último período da graduação.

Em seguida, foi realizado um estudo de campo, tendo duração de dois meses (outubro e novembro de 2017) com aplicação de entrevista semiestruturada composta por oito questões, sendo estas de caráter discursivo e/ou de múltipla escolha, direcionadas a temática proposta. Dessa forma, foram abordadas questões relacionadas à concepção da disciplina de Metodologia Científica na graduação, assim como a percepção das metodologias utilizadas para a produção científica e sua influência no cotidiano social e profissional.

Para a execução deste estudo foram selecionados 31 (trinta e um) discentes, dos quais 15 (quinze) haviam acabado de cursar a disciplina de Metodologia, sendo denominados nesse estudo por ingressantes, e 16 (dezesseis) estudantes que estavam concluindo o curso com a apresentação do TCC, denominados aqui por egressos.

\section{RESULTADOS E DISCUSSÃO}

\section{Concepcão da Disciplina de Metodologia Científica na Graduacão}

Os dados obtidos mostraram que a maioria dos entrevistados que ingressaram na graduação em questão (87\%), não apresentava nenhum conhecimento prévio a respeito de Metodologia Cientifico, sendo que os demais afirmaram ter conhecimento oriundo do Ensino Médio, constatando-se a necessidade de repensar os papéis dos atores envolvidos em sala de aula da Educação Básica, de forma que o estudante tenha oportunidades de interagir com o 
objeto de estudo e com seus pares para organizar o pensamento e elaborar explicações sobre o mundo, utilizando-se de conceitos científicos (URSI E SCARPA, 2016).

Todavia, $13 \%$ dos estudantes do $8^{\circ}$ período afirmaram que havia um conhecimento prévio sobre Metodologia Científica, formulado a partir do Ensino Médio e 31\% argumentaram conhecer ou terem ouvido falar anteriormente a graduação, mas não especificaram a origem. Destarte, embora haja desconhecimento por parte dos mesmos é possível constatar que essa metodologia dialética do conhecimento perpassa todo trabalho docente-discente, estruturando o desenvolvimento e o processo de construção do conhecimento escolar (GASPARIN, 2007).

Os dados ora apresentados corroboram com Kauark, Manhães e Medeiros (2010), quando afirmam que, muitos não percebem a importância destes conhecimentos para o dia a dia, talvez por falhas na metodologia de ensino, por vezes pouco estimulante.

Com relação às metas exigidas pela disciplina de Metodologia Científica ministrada para os graduandos em questão, 53\% dos ingressantes e $69 \%$ dos egressos afirmaram que o método enriquece o conhecimento, instigando o discente a crescer profissionalmente. Pinto (2009) acrescenta que quando incorporado a uma forma de trabalho ou de pensamento, esse conhecimento leva o individuo a adquirir novos hábitos e posturas. Porém, $40 \%$ dos entrevistados argumentaram ter dificuldades na disciplina, havendo a necessidade de mais tempo e produções de trabalhos para melhorar o conceito cientifico. Mas, o objetivo da disciplina é eminentemente prático e deve servir para estimular os alunos na busca de respostas às suas dúvidas (KAUARK, MANHÃES E MEDEIROS, 2010).

Nesse sentido, o conhecimento e a aprendizagem tornam-se perceptível no decorrer do curso, porém a demanda de aula é insuficiente para a absorção do conteúdo, tendo em vista que de inicio o aluno "copia" as informações repassadas sobre orientação do professor, onde passam a reproduzir sem nada acrescentar. Demo (2005) acrescenta que posteriormente o estudante, põe-se a buscar e elaborar o pensamento próprio, que vai sendo aprimorado, à medida que a pesquisa transcorre.

\section{Percepcão das Metodologias para a Producão Científica}

A respeito dos métodos utilizados na construção de trabalhos científicos, das ferramentas para obtenção dos dados e das exigências estabelecidas pela Associação Brasileira de Normas Técnicas (ABNT), 80\% dos ingressantes na graduação e 50\% dos egressos, afirmaram ter pouco ou nenhum conhecimento inicial sobre esses aspectos.

Ao serem indagados em quais aspectos supracitados teriam maior deficiência, $80 \%$ dos ingressantes asseguraram ter pouco conhecimento a cerca dos métodos e $73 \%$ para regras da ABNT e ferramentas para obtenção dos dados (Gráfico 1), evidenciando a necessidade de se 
repensar na inserção da disciplina de Metodologia Cientifica na matriz curricular do Ensino Médio (MAIA, 2008). Estes dados atestam também as dificuldades enfrentadas pelos discentes, uma vez que na universidade o estudante irá se deparar com diversos campos de atuação na qual deverá ser versátil e criativo (CAMPOS, SANTOS E SANTOS, 2009).

Gráfico 1 Percepção dos estudantes a respeito de regras, ferramentas e métodos utilizados na construção de trabalhos científicos ao ingressarem na graduação em Licenciatura. Fonte: Rodrigues, 2018.

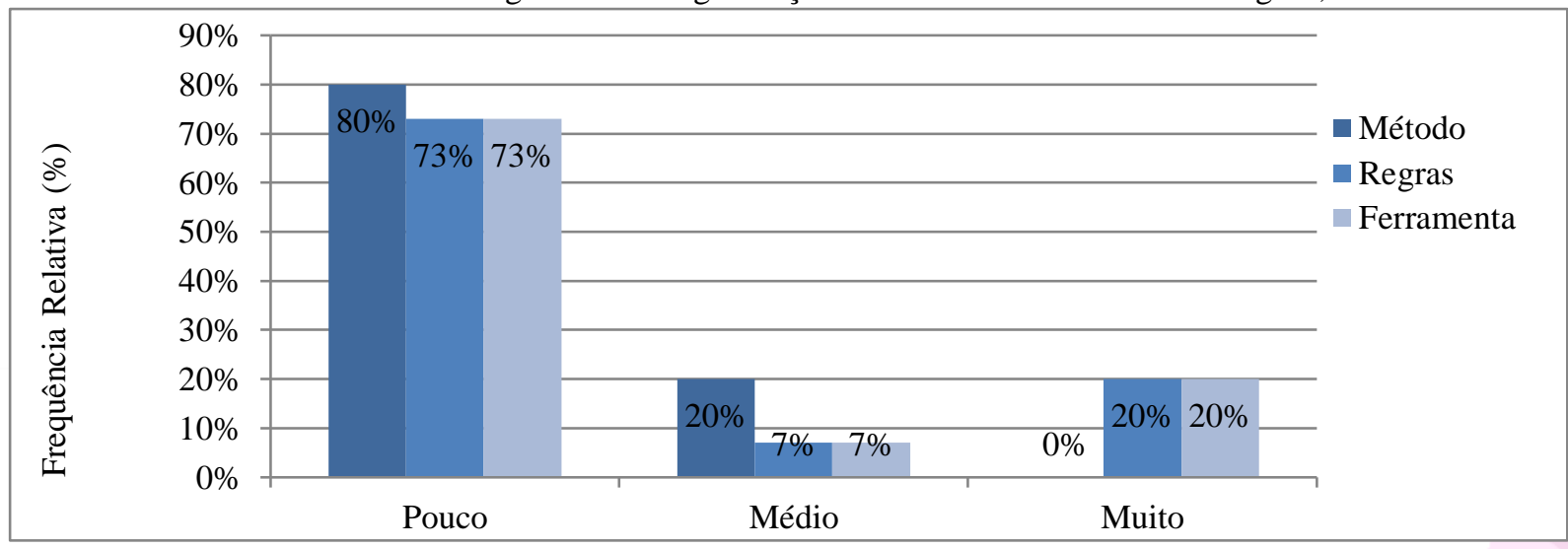

Vale salientar que, após ter cursado a disciplina de Metodologia Científica a percepção do estudante a cerca dos aspectos apresentados anteriormente foi consideravelmente melhor, uma vez que $93 \%$ dos ingressantes e $75 \%$ dos egressos consideraram haver um conhecimento regular perante os mesmos, haja vista que tais saberes são necessários para realização das atividades, onde os discentes demonstram maior segurança, tanta na resolução de problemas teóricos, quanto práticos (BARIN, 2009) e são construídos ou aprimorados ao longo da formação e carreira profissional (BRIGHENTI, BIAVATTI E SOUZA, 2015).

Os dados apresentados evidenciaram também que $60 \%$ dos estudantes ingressantes e $69 \%$ dos egressos, apresentaram maior dificuldade no entendimento de como os métodos utilizados podem auxiliar na construção de trabalhos científicos, o que demonstra à necessidade de reavaliar a inserção do método científico nas disciplinas dos cursos de graduação que são ministradas posteriormente a de Metodologia Científica, de forma que este passe a ser vivenciado em todas as atividades desenvolvidas, assim poderá ser mais amplo e com maior abrangência, uma vez que a ciência não fica presa aos conceitos e teorias, e a prática científica é fundamental para o seu desenvolvimento. Haja vista que, teoria e prática têm que estar interiorizada no pesquisador (OLIVEIRA E VALENÇA, 2015).

Com relação ao conhecimento a respeito dos diferentes gêneros textuais usados para construção do conhecimento científico, assim como os utilizados para apresentar os dados científicos, os estudantes do $4^{\circ}$ período citaram a relevância dos seguintes destaques; $33 \%$ mencionaram a Pesquisa Bibliográfica como o instrumento de maior relevância ou excelente, Resumo e Resenha como regular para 60\% desses, seguido por Artigo Científico e Fichamento 
com 67\% dos entrevistados considerando-os com nenhuma relevância (Gráfico 2).

Gráfico 2. Percepção dos estudantes do $4^{\circ}$ período ao ingressarem na graduação em Licenciatura com relação às produções acadêmicas. Fonte: Rodrigues, 2018.

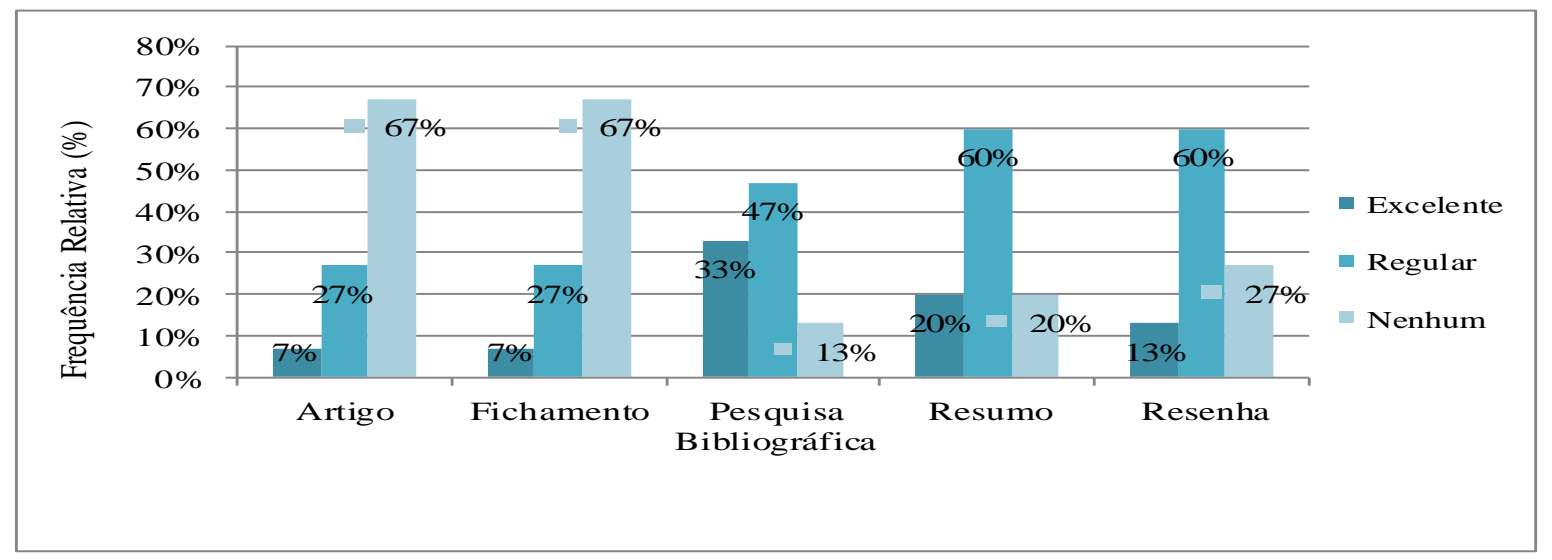

Porém para o $8^{\circ}$ período, $69 \%$ dos entrevistados afirmaram que a Pesquisa Bibliográfica apresenta relevância regular, seguido por Fichamento com 44\% com nenhuma e 25\% citaram Artigo como um excelente instrumento (Gráfico 3). Deste modo, a variedade demonstrada nos índices obtidos, confirma a colocação de Silva (2016) quando assegura que ao ingressar na universidade o estudante depara-se com situações pouco comuns a sua realidade, até então, havendo relativa confusão devido as complexidades apresentadas por tais ferramentas.

Gráfico 3. Percepção dos estudantes do $8^{\circ}$ período ao ingressarem na graduação em Licenciatura com relação às produções acadêmicas. Fonte: Rodrigues, 2018.

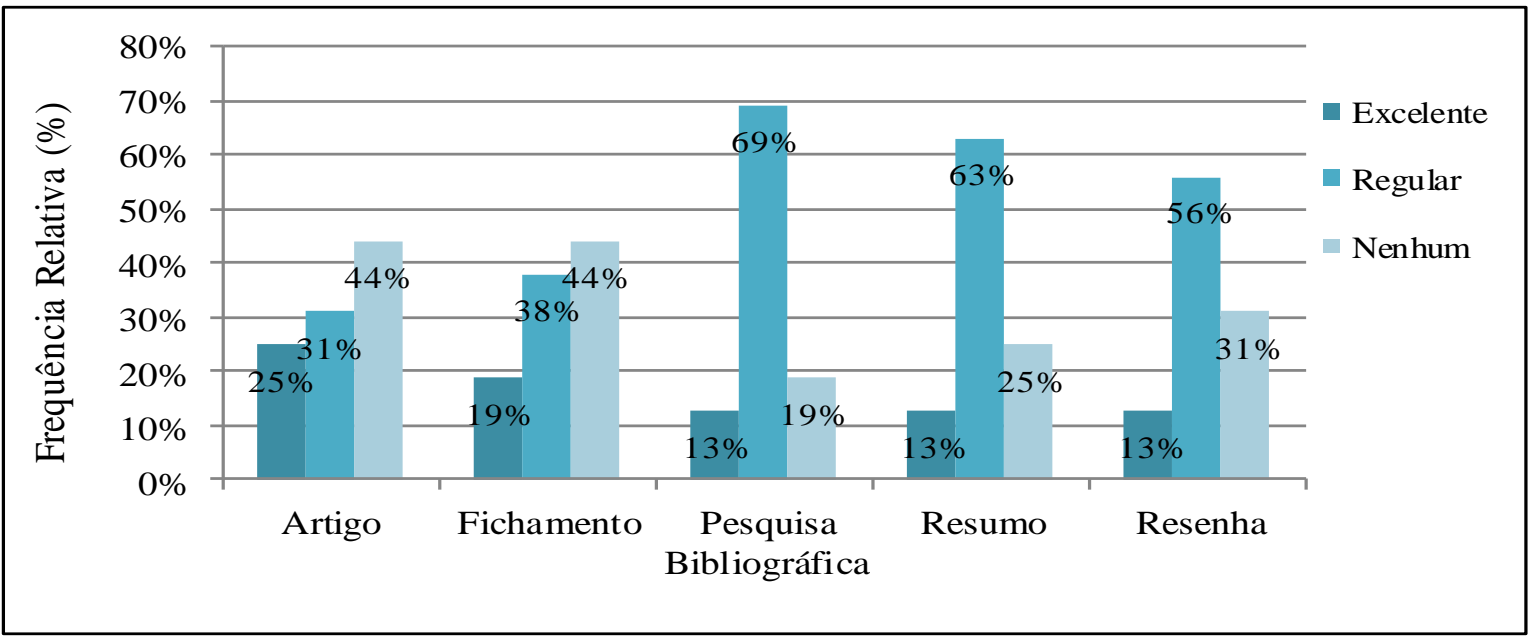

Entretanto, mesmo após vivenciar e ter contato com esses diferentes gêneros textuais abordados pela disciplina de Metodologia Cientifica, constatou-se que ainda houve variação, pois para os discentes do $4^{\circ}$ período a Resenha passou a ser considerada como um instrumento regular para $80 \%$ dos entrevistados, a Pesquisa Bibliográfica passou a ser avaliada como excelente por $47 \%$ destes, e o Fichamento e Artigo como nenhum por $20 \%$, o que pode demonstrar que os estudantes não possuem o conhecimento correto e necessário sobre os diferentes gêneros textuais, necessitando de uma nova abordagem tanto para o desenvolvimento 
na Educação Básica, quanto para a graduação, devendo tais instrumentos ser vivenciados em todas as disciplinas componentes das matrizes curriculares.

Ressalta-se que, esse mesmo comportamento foi constatado nos estudantes que estavam construindo o TCC. Segundo Campos, Santos e Santos (2009), havendo o incremento nos índices de regularidade e excelência a respeito do conhecimento sobre produções cientifica, ampliar-se-ia o objetivo proposto que é a importância científica na formação do profissional que busca contribuir para o aumento do conhecimento.

\section{Influência no Cotidiano Social e Profissional do Graduando}

De acordo com os ingressantes, os métodos científicos ajudaram a melhorar suas produções acadêmicas, uma vez que os mesmo auxiliaram no desenvolvimento da escrita e aprimoramento dos conhecimentos, devido às regras e normas desenvolvidas para a construção dos trabalhos científicos.

Para os egressos, através da inserção do Método Científico os mesmos passaram a ter uma visão mais ampla e contextualizada com relação a produções textuais, sendo capazes de produzir trabalhos mais consistentes.

Assim, o conhecimento sobre Metodologia Cientifica auxiliará na vida profissional e/ou pessoal, como explanado pelos estudantes do $4^{\circ}$ período que salientaram a importância das produções acadêmicas com o intuito de enriquecer o currículo e torná-los críticos a determinadas situações, como também foi observado por Silva (2016), que considerou um fator importante e decisivo em determinadas situações, sejam trabalhistas ou principalmente se pretender continuar a se especializar na carreira acadêmica.

No entanto, os egressos afirmaram que a influencia ocorre somente no meio profissional, pois ajudaria no processo de construção de pesquisa, favorecendo na carreira docente ou em outras áreas, uma vez que exigem do profissional não só conhecimento teórico, mas a pratica baseada em produção de conhecimento, como observado por Costa e Silva (2016).

\section{CONCLUSÕES}

Os métodos, ferramentas e regras instigam a gerar uma pesquisa, desenvolvendo o senso crítico no pesquisador, sendo capaz de formular pensamento maduro e embasado em leituras e observações, tendo assim um arcabouço confiável e linear. Desta forma, torna-se fundamental a inclusão de Metodologia Científica na Educação Básica, através do ensino por investigação, uma vez que é capaz de mudar o estudante, gerando conhecimento, para o cotidiano acadêmico.

Salienta-se também que, na graduação é essencial a vivencia de métodos científicos não só na disciplina de Metodologia Científica, mas de um modo geral, haja vista que tais métodos 
precisam ser vivenciados na teoria e prática, exigindo tempo e disponibilidade, só assim será capaz de gerar impacto na vida profissional, pessoal e cultural ocasionando transformações na sociedade.

\section{REFERÊNCIAS}

BARIN, C, S; CUNHA, M, E, T, da; ELLENSOHN, R, M. Construindo o conhecimento através de projetos de pesquisa: Relato de uma experiência. I Simpósio Nacional de Ensino de Ciências e Tecnologia - 2009.

BRASIL, Lei de Diretrizes e Bases da Educação Nacional. Lei Federal no 9.394/96, de 20 de dezembro de 1996. Diário Oficial [da] República Federativa do Brasil, Poder Executivo, Brasília, DF, 23 dez. 1996. Seção 1, p. 27833.

BRIGHENTI, J; BIAVATTI, V, T; SOUZA, T, R, de. Metodologia de EnsinoAprendizagem: uma abordagem sobre a percepção do aluno. Revista GUAI, Florianópolis, V.8, N.3, P.281-304. 2015.

CAMPOS, F, G, G; SANTOS, R, F; SANTOS, F, C, P, e. A importância da pesquisa cientifica na formação profissional dos alunos do curso de educação física do unilestemg. MOVIMENTUM - Revista Digitai da Educação Fisica - Ipatinga: Unileste-MG - V,4 - N.2 - Ago./Dez. 2009.

COSTA, L, R, da, S; SILVA, M, A, A, da. Dificuldades vivenciadas na elaboração de artigos científicos: percepção de discente do curso de licenciatura em matemática da UFPE - CAA. III CONEDU. Congresso Nacional de Educação. João Pessoa, PB. 2016.

DEMO, P. Saber pensar. 4 ed. São Paulo: Cortez, 2005 (Guia da Escola Cidadão v.6).

FALCÃO-JUNIO, M, A, G; SILVA, M, S; BEZERRA, M, P; NETO, E, A, de, O; SILVA, G, $M$, da. As dificuldades na elaboração de artigos científicos para alunos de graduação na Área de Ciências da Informação. Encontro Regional de estudantes de Biblioteconomia, documentação, Ciência e Gestão da Informação EREBD N/NEgetão CARIRI 2011- 2012.

FREITAS, T, C, S. A percepção dos discentes sobre dificuldades na produção do trabalho acadêmico. IX APENDSUL Seminário de pesquisa em educação de região Sul. 2012 FVRB.

GASPARIN, J, L. Uma didática para a pedagogia histórico-critico. 4. Ed. Revista e ampliada. Campinas, SP: Autores associado, 2007. (Coleção Educacional Contemporânea).

GERHARDT, T, E; SILVEIRA, D, T. Método de pesquisa. Coordenado pela Universidade Alberta Brasil - UAB/UFRGS e pelo curso de graduação Tecnologia - planejamento e gestão para o desenvolvimento Rural da SEAD/UFRGS. - Porto Alegre: Editorada UFRGS, 2009.

KAUARK, F, da. S; MANHÃES, F, C; MEDEIROS. C. H. Metodologia da pesquisa: guia 
prático / Fabiana Kauark, Fernanda Castro Manhães e Carlos Henrique Medeiros. - Ita- buna : Via Litterarum, 2010.

LIBÂNIO, J, B. Introdução à vida intelectual. São Paulo: Loyola 2001.

MAIA, R, T. A Importância da disciplina de Metodologia Cientifica no desenvolvimento de produção acadêmica de qualidade no nível superior. Revista Urutágua - revista acadêmica multidisciplinar (DCS/VEM). No 14 dez 07/jan./fev./mar 2008 Quadrimestral Maringá - Paraná - Brasil.

OLIVEIRA, T, A, B, de; VALENÇA, K, F, P. A importância da metodologia cientifica para o Ensino e Aprendizagem no ensino superior. EDUCRE PUCPR 26 a 29/10/2015.

PINTO, M, J, F. A metodologia como ferramenta na comunicação Empresarial. In: Congresso Brasileiro de Comunicação Empresarial 2009.

PRODANOV, C, C. Método de trabalho Científicos [ recurso eletrônico ]: Métodos e Técnicas da pesquisa e do trabalho acadêmico / Cleber Cristiano Prodanov, Ernani Cesar de Freitas - 2 ed. Novo Hamburgo: Feevale 2013. 42 a 80 p.

SAMPAIO, T, C, de, A, S. A importância da Metodologia da pesquisa para produção de conhecimento científico nos cursos de pós - graduação. Revista do programa de pós graduação em direito da Universidade Federal da Bahia - 25. 2013.

SANTOS, V, C; ANJOS, K, F, dos; ALMEIDA, O, S. A percepção de formandos sobre a pesquisa em enfermagem no curso de graduação. Ver. Enferm. UFSM 2013 jan./abril; 3(1): $144-154$.

SEVERINO, A, J. Metodologia do trabalho científico. 21 a ed. São Paulo: Cortez, 2000.

SILVA, M, das, M, de, S. A importância do conhecimento científico na universidade e sua contribuição para a semana científica da faculdade r. Sá. X SEMANA DE INICIAÇÃO CIENTÍFICA DA FACULDADE R.SÁ.01, 02 e 03 de junho de 2016. Picos - PI.

URSI, S; SCARPA, D, L. Ensino de Ciências por investigação: sequencia didática "Mata Atlântica - Restinga" / organizadoras Suzana Ursi; Daniela Lopes Scarpa. -- São Paulo: Instituto de Biociências, Universidade de São Paulo, 2016. 39 p. 